\title{
REVISIÓN DEL PROCESO DE VALORIZACIÓN DE LOS RECURSOS BASE DEL TURISMO INDUSTRIAL
}

Amaia Makua

Universidad de Deusto

\begin{abstract}
Resumen: El turismo industrial es una manifestación relativamente reciente del turismo cultural. Si bien la delimitación de su alcance temático y temporal es objeto de discusión entre la doctrina, paulatinamente se adopta una definición más integradora, que comprende el conjunto de manifestaciones materiales e inmateriales, asociadas a la cultura productiva capitalista del pasado y del presente. El objetivo de este texto es analizar el proceso de valoración social, cultural e institucional de los restos productivos y de la industria viva para pronosticar su impacto en la concepción de una oferta integradora de turismo industrial, representadora fidedigna de la cultura de la industria pasada y presente.
\end{abstract}

Palabras clave: turismo industrial, Revolución Industrial, desindustrialización, patrimonio cultural, patrimonio industrial, restos industriales, industria viva, valorización de los recursos.

Resumo: Revisión do proceso de valorización dos recursos base do turismo industrial O turismo industrial é unha manifestación relativamente recente do turismo cultural. Aínda que a delimitación do seu alcance temático e temporal é obxecto de discusión entre a doutrina, paulatinamente foi adoptándose unha definición máis integradora, que comprende o conxunto de manifestacións materiais e inmateriais, asociadas á cultura produtiva capitalista do pasado e do presente. O obxectivo deste texto é analizar o proceso de valoración social, cultural e institucional dos restos produtivos e da industria viva para prognosticar o seu impacto na concepción dunha oferta integradora de turismo industrial, representante fidedigna da cultura da industria pasada e presente.

Palabras clave: turismo industrial, Revolución Industrial, desindustrialización, patrimonio cultural, patrimonio industrial, restos industriais, industria viva, valorización dos recursos.

Abstract: Review of the uses applied to basic industrial tourism resources Industrial tourism emerged relatively recently as a form of cultural tourism. Although defining its boundaries in terms of scope and time remains the object of academic discussion, a more integrating definition appears to have been reached, which includes a series of material and immaterial issues, related to the capitalist productive culture of both past and present. The aim of this text is to analyse the social, cultural and institutional use of former production and manufacturing facilities as well as living industry in order to forecast their impact on the creation 
of an integrating industrial tourism offer, which represents past and present industrial culture in a true and faithful manner.

\section{INTRODUCCIÓN}

A la hora de plantear la cuestión de estudio del presente artículo tenemos en consideración dos hechos:

- Por una parte, el turismo industrial es una manifestación emergente del turismo cultural. Actualmente se va imponiendo una visión amplia e integradora del concepto que comprende tanto actividades basadas en elementos pertenecientes a otras épocas, como en organizaciones en actividad.

- Por otra parte, en el proceso de generación de oferta turística desempeña un papel fundamental la identificación y posterior selección de los recursos, que son la materia prima para crear el producto turístico, que posteriormente será promocionado y comercializado (San Salvador del Valle y Makua, 2005).

Dado el carácter reciente y novedoso de esta rama del turismo cultural, cabría cuestionarse si los recursos en los que se apoya, a los que ahora se presume una capacidad de atracción turística, gozan de un valor social, cultural e institucional consolidado. Basándonos en este pensamiento planteamos como hipótesis de partida que la insuficiente y/o desigual valoración social, cultural e institucional de los restos productivos y de la industria viva dificulta la concepción y el desarrollo de una oferta de turismo industrial integradora que represente de manera fidedigna la cultura de la industria pasada y presente.

El examen de los textos académicos más relevantes sobre el tema nos permitirá confirmar o refutar nuestra hipótesis de trabajo.

En primer lugar, exponemos el fenómeno causante de la existencia de los recursos industriales pretéritos y actuales: la industrialización y consecutiva desindustrialización. A continuación, examinamos los factores que desencadenan el proceso de valoración social, cultural e institucional de los restos productivos y de la industria viva. Este análisis nos permite desarrollar una serie de conclusiones, en base a las cuales, confirmaremos o rebatiremos la hipótesis planteada.

\section{LA INDUSTRIALIZACIÓN Y DESINDUSTRIALIZACIÓN EN EUROPA}

El curso de los acontecimientos económicos y sociales que definen los dos últimos siglos transforman el modo en que la persona y la comunidad se relacionan con su pasado más reciente. En Europa el fenómeno de la industrialización tiene lugar en distintas etapas -Primera, Segunda y Tercera Revolución Industrial- a las que sigue una ulterior desactivación del proceso a partir de los años setenta del siglo XX. 


\subsection{EL PROCESO INDUSTRIALIZADOR}

La industrialización acompaña al capitalismo industrial en su fase de plenitud. $\mathrm{Su}$ origen e hitos más sobresalientes tienen lugar en países de Europa -tales como Gran Bretaña, Alemania, Francia y Bélgica- así como en los Estados Unidos (Santacreu, 1991 y Benito, 2002). Se produce, primero, un auge de la industria pesada y, posteriormente, de la industria de transformación, basado en los avances tecnológicos y energéticos. (Benito, 2002). La producción fabril o "maquinofactura" (Capel y González, 2010:1) sustituye a los métodos artesanales y manufactureros (Pardo, 2002) y genera una de las mayores transformaciones históricas de la humanidad, que se sitúa en otra era (Casanelles, 2007). La vida de miles de personas cambia de un modo comparable al que tiene lugar entre el Neolítico y la Edad de Bronce (TICCIH, 2003).

A pesar de tratarse de un proceso heterogéneo, experimentado y evocado de forma particular por los países, en fases y tiempos diversos, (Edwards y Llurdés, 1996 y Álvarez, 2001) es posible acotar, desde el punto de vista histórico-económico, tres etapas clave, denominadas también revoluciones industriales, cada una de las cuales se relaciona de un modo particular con el pasado reciente (Storm, 2008).

Las tres fases tienen una complejidad mucho más importante que los hechos tecnológicos que las caracterizan (Casanelles y Fernández, 1994); sin embargo, la consideración de lo científico permite, de una manera obviamente simplificada, realizar una aproximación sintética al fenómeno. A continuación aportamos una breve descripción de las etapas industrializadoras y del modo en que la industria y el patrimonio se encuentran.

1. La Primera Revolución se caracteriza por la energía del vapor, el hierro colado y el ferrocarril (Casanelles y Fernández, 1994 y Storm, 2008). Inicia su andadura en las últimas décadas del siglo XVIII en Gran Bretaña y, desde ahí, se extiende durante la primera mitad del siglo XIX a otros puntos occidentales, como Bélgica, Alemania o Francia. Supone importantes cambios en el proceso de trabajo, ahora dividido en elementos y desarrollado en un edificio concreto: la fábrica. Socialmente las transformaciones que el modelo productivo introduce se perciben por determinadas capas como un desvanecimiento del modo de vida agrario y provocan una respuesta pública y social que pretende salvaguardar algunos restos representativos del modo de vida en vías de extinción. La industria representa en esta etapa novedad e innovación y, por tanto, casi una antítesis del pasado (Storm, 2008). Los primeros países industrializados son también los pioneros a la hora de tomar conciencia sobre la importancia de este proceso transformador cuando se inicia la Segunda Revolución, que dota de nuevas dimensiones al fenómeno. La sensibilidad y el interés por el progreso de las ciencias y de las técnicas conduce a la apertura de museos relacionados con dichas temáticas en Francia, como el Museo de Fábrica de Saint-Etienne o el Museo Histórico de los Tejidos de Lyon (Santacreu, 1991). 
2. La Segunda Revolución se produce al entrar en el siglo XX y viene marcada por la introducción de la electricidad y el petróleo (Casanelles y Fernández, 1994). El trabajo se racionaliza y se implantan medios de producción masiva. El obrero es remunerado no por el producto finalizado, sino en función del tiempo que emplea en la producción. Consecuente con este cambio de paradigma los patrones plantean nuevas metodologías para organizar el trabajo, buscando obtener la máxima eficiencia de la fuerza obrera. Se adoptan dos soluciones principales: la gestión científica, representada por Frederick W. Taylor y la cadena de montaje, vinculada a Henry Ford. Tales cambios impulsan el surgimiento de la sociedad de consumo, caracterizada por la producción y el consumo en masa; la mejora en la efectividad de los costes de producción permite al trabajador acceder al nuevo mercado de bienes. En este contexto la reacción social frente al pasado presenta distintas manifestaciones. En los países occidentales se establecen instituciones generales que propician la relación con el ayer, con el fin de sentar las bases de la sociedad moderna. En un plano industrial, la etapa anterior se utiliza para contrastar la modernidad no sólo de la industria, sino de la sociedad en su totalidad. La comparación entre la maquinaria nueva y la antigua sirve para resaltar aún más el valor moderno. Este interés social por el futuro se acrecienta hasta alcanzar su máximo apogeo en las décadas de mediados del siglo XX. Las referencias al pasado son menores en una sociedad que centra sus miradas en el futuro, tiempo marcado por un progreso social y material que afecta al espacio y transforma la vida cotidiana con materiales como el plástico, el cemento y el asfalto. En definitiva, durante los últimos años del siglo XIX y siguientes décadas la Segunda Revolución centra su atención en los principios de la historia industrial con el fin de contrastarlos con la entonces industria moderna (Storm, 2008).

3. La Tercera Revolución se remonta a mediados de los años setenta y se materializa a través de los avances en la automatización y de la aplicación de tecnologías nuevas -la electrónica, los plásticos y las fibras sintéticas- a los procesos productivos y de gestión (Casanelles y Fernández, 1994 y Capel y González, 2010). Tales novedades propician una transformación de gran calado en los modelos de producción industrial que conduce a una crisis productiva estructural. Sus efectos se dejan sentir de manera anticipada en algunos sectores, como el textil-golpeado a finales de los 50 y en los 60- y las industrias del hierro y acero empiezan a notar la crisis en mayor grado en los 70 y 80, años en los que tiene su mayor impacto. En lo que se refiere al modo de producción, la tercera etapa se caracteriza por la especialización flexible de los trabajadores, el incremento del consumo y la globalización de los mercados. En este contexto surge la empresa en red, cuya ventaja competitiva no son ya sus procesos productivos, sino su capacidad para vender en una sociedad que valora no sólo el factor precio, sino también los valores simbólicos 
de los productos. A partir de los años 70 el optimismo de la década anterior es progresivamente reemplazado por nociones del futuro que se apoyan, cada vez más, en referencias pretéritas. Se da una mayor conciencia e interés por el pasado, por lugares y artefactos industriales valorados ya como historia y patrimonio. Esta consideración se produce por la concurrencia de factores tales como el replanteamiento general que Occidente hace de su sociedad, los vertiginosos cambios en los paisajes industriales y la crisis estructural (Storm, 2008). Para Casanelles y Fernández (1994) el factor clave es el cambio, sometido a tal aceleración que provoca entre los colectivos del mundo de la cultura

“(...) la necesidad de preservar unos materiales, unos objetos, unos restos que, aunque no entraban dentro del concepto tradicional de obra de arte, de piezas artísticas, eran el testimonio del mundo del trabajo $y$ de la vida cotidiana de la sociedad y aportaban unas informaciones cualitativas que nunca se habían conservado" (Casanelles y Fernández, 1994: 52).

El creciente interés por los ambientes industriales como representaciones del pasado es uno de los agentes que motiva la ampliación de la noción de patrimonio (Storm, 2008).

La tabla 1 representa de manera resumida los factores tecnológicos, laborales y sociales, así como la reacción social frente a los restos de la etapa precedente. 
Tabla 1. Caracterización tecnológica, laboral y social de las revoluciones industriales y su relación con los restos de etapas anteriores.

\begin{tabular}{|c|c|c|c|c|}
\hline Fase & Tecnología & Trabajo & Sociedad & $\begin{array}{l}\text { Relación con la etapa } \\
\text { anterior }\end{array}$ \\
\hline 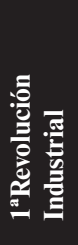 & $\begin{array}{l}\text { Máquina de } \\
\text { vapor. } \\
\text { Hierro colado. } \\
\text { Ferrocarril. }\end{array}$ & $\begin{array}{l}\text { De la } \\
\text { manufactura a la } \\
\text { maquinofactura. } \\
\text { Se divide en } \\
\text { elementos. } \\
\text { Se desarrolla en la } \\
\text { fábrica. }\end{array}$ & $\begin{array}{l}\text { Se desvanece la } \\
\text { sociedad agraria. } \\
\text { Interés por el } \\
\text { progreso. }\end{array}$ & $\begin{array}{l}\text { Salvaguarda de los restos } \\
\text { de la vida agraria. } \\
\text { Primeros museos de las } \\
\text { ciencias y las técnicas }\end{array}$ \\
\hline 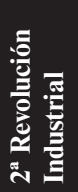 & $\begin{array}{l}\text { Electricidad. } \\
\text { Petróleo. }\end{array}$ & $\begin{array}{l}\text { Se gestiona } \\
\text { científicamente. } \\
\text { Se introduce } \\
\text { la cadena de } \\
\text { montaje. }\end{array}$ & $\begin{array}{l}\text { Sociedad de } \\
\text { consumo. }\end{array}$ & $\begin{array}{l}\text { Instituciones generales } \\
\text { para relacionarse con el } \\
\text { pasado. } \\
\text { Referencias del pasado } \\
\text { para ensalzar el futuro. }\end{array}$ \\
\hline 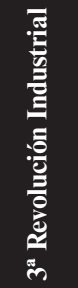 & $\begin{array}{l}\text { Automatización. } \\
\text { Nuevas } \\
\text { tecnologías. } \\
\text { Aplican a } \\
\text { procesos } \\
\text { productivos y de } \\
\text { gestión. }\end{array}$ & $\begin{array}{l}\text { Especialización } \\
\text { flexible. } \\
\text { Incremento del } \\
\text { consumo. } \\
\text { Empresa en red. }\end{array}$ & $\begin{array}{l}\text { Globalización } \\
\text { Desindustrialización. } \\
\text { Sociedad de la } \\
\text { información. } \\
\text { Crisis estructural. }\end{array}$ & $\begin{array}{l}\text { Mayor conciencia e interés } \\
\text { por el pasado. } \\
\text { Ampliación del concepto } \\
\text { patrimonial, que incluye } \\
\text { lo industrial. } \\
\text { Lo pasado se convierte en } \\
\text { palanca de regeneración. }\end{array}$ \\
\hline
\end{tabular}

Fuente: elaboración propia a partir de Casanelles y Fernández (1994), Benito (2002), Storm (2008) y Capel y González (2010)

\subsection{LA DESINDUSTRIALIZACIÓN}

La constante innovación productiva y la velocidad de recambio tecnológico que tiene lugar desde los años 70 del siglo XX, junto con la irrupción de las denominadas nuevas tecnologías, inician una crisis estructural en el sistema capitalista que se traduce en una obsolescencia tecnológica cada vez más rápida de los procesos productivos y de las instalaciones, que lleva a la ruina económica a numerosas empresas (Capel, 1996b; Benito, 2002; Arocena, 2004 y Storm, 2008). Sus efectos demoledores se dejan sentir, con especial fuerza, en las regiones industriales más tradicionales de Europa y en sectores maduros, como el minero, el siderúrgico, el de la construcción naval o el textil (Benito, 2002 y Hospers, 2002).

Los sucesivos abandonos, cierres y reubicaciones de las fábricas se convierten en "un fenómeno de proporciones a veces impresionantes" (Pardo, 2008:11) que acarrea una serie de consecuencias y retos para los agentes sociales de los lugares afectados por la crisis. El efecto más elocuente sobre el territorio es el derribo de viejas fábricas no adaptadas a las nuevas exigencias y la aparición de áreas industriales 
abandonadas en el centro de las ciudades (Capel, 1996b; Benito, 2002; Arocena, 2004 y Storm, 2008). Al desmantelamiento de estructuras manufactureras hay que añadir los cambios que, desde la década de los años sesenta, se introducen en el transporte y que afectan a sus estructuras. Tales cambios se deben a la generalización de nuevos sistemas, como el camión, los contenedores y el avión, que conllevan "el cierre y desmantelamiento de líneas férreas así como una profunda transformación de los puertos" (Capel, 1996b:27). Los restos del pasado más reciente son percibidos la mayor parte de las veces como obstáculos físicos carentes de interés, costosos de eliminar y sin la antigüedad necesaria para dotarles del valor que el patrimonio histórico de épocas más lejanas en el tiempo tiene (Arocena, 2004).

La proliferación de los baldíos industriales alerta a los responsables públicos locales en aquellos lugares donde el fenómeno se manifiesta con mayor virulencia. Las primeras reacciones de los poderes públicos intentan resolver un problema que va en aumento y que constituye un factor desestructurante que desvaloriza la imagen y reduce el atractivo territorial. Las medidas tomadas por diversos gobiernos europeos en la década de los 80 se muestran insuficientes para atajar la crisis y no logran evitar ni el cierre de fábricas, ni la liquidación de negocios ni los despidos masivos de trabajadores (Benito, 2002). Según esta misma autora, la problemática presenta múltiples caras: "degradación medioambiental y física del espacio urbano, contaminación de suelos, especulación, destrucción de actividad económica, desempleo y tensión social” (Benito, 2002:215). Se trata de impactos de índole urbanístico, arquitectónico, económico, social y también emotivo, que inciden negativamente en la imagen de las ciudades y constituyen rémoras a la reconversión y estimulación del desarrollo territorial; tales impactos, por otra parte, hacen reflexionar sobre las posibles alternativas de recuperación de esos lugares con una finalidad distinta de la originariamente concebida, con funciones nuevas que permitan relanzar económicamente estas zonas decrépitas (Capel, 1996b y Pardo, 2008).

En paralelo a la desaparición de la industria se produce una evolución de una economía manufacturera a una de servicios y surge la ciudad postindustrial. La terciarización económica supone apartar espacial y culturalmente de la industria tradicional a los ciudadanos occidentales, que pierden el contacto cotidiano y el conocimiento directo del mundo industrial. En este marco postmoderno las ciudades pugnan por obtener inversiones públicas y privadas (Capel, 1996b y Andreadakis y Davis, 1998). Y los restos industriales, considerados cada vez más como patrimonio, dejan de "ser una rémora para las administraciones y se convierte en un instrumento de desarrollo local" (Romero, 2006:1).

En definitiva, observamos cómo las transformaciones debidas a este proceso de ida y vuelta configuran el modo en que la sociedad se relaciona con su pasado más reciente. Son los países que lo experimentan en mayor medida los que muestran una sensibilidad más temprana hacia la nueva cultura industrial. Con la Segunda Revolución se produce una recuperación de elementos de la primera etapa con el fin de 
ensalzar el progreso que representa esta nueva era. El advenimiento de la tercera fase acarrea el desmantelamiento de estructuras productivas y de transporte. Y, como reacción ante la pérdida de elementos del pasado más inmediato, surgen movimientos académicos y sociales, cuyas demandas acaban por hacerse escuchar entre los poderes públicos; éstos finalmente vislumbran la capacidad regeneradora de los lugares en declive y reconocen su valor en un plano institucional y legal. Los siguientes puntos detallan cómo se desarrolla el proceso de valorización, primero de los vestigios y, después, de la industria activa.

\section{EL PROCESO DE VALORIZACIÓN DE LOS RESTOS INDUSTRIALES}

De ser considerados una carga heredada del declive económico, los restos industriales son paulatinamente apreciados, conforme se produce una mayor sensibilidad social, una ampliación de los valores asociados al patrimonio, una consideración de su potencial para la regeneración de los baldíos y, por último, un reconocimiento institucional y legal en el plano internacional y nacional.

\subsection{LA VALORACIÓN NEGATIVA INICIAL DEL PATRIMONIO INDUSTRIAL}

$\mathrm{Si}$, desde el punto de vista sociocultural, el concepto de patrimonio cultural es aun hoy en día novedoso, el industrial es prácticamente inédito. Un factor determinante de la visión restrictiva es el enfoque que historiadores y antropólogos españoles sostienen sobre la industria. Su lectura es reduccionista -prácticamente de lo material- y sesgada, basada en los prejuicios hacia lo moderno, urbano e industrial que folkloristas y etnógrafos de mediados del siglo XIX imponen. Éstos entienden que la industria y lo urbano son etnicidas que desestructuran la sociedad porque se asocian con la modernidad, el mercado, el capitalismo, el cambio social, el multiculturalismo a través de la secularización y la inmigración (Homobono, 2008). Tal análisis fundamenta la idea, vigente en los inicios de la industrialización, de que la fábrica y otras estructuras industriales y artefactos constituyen la misma contradicción al patrimonio (Storm, 2008).

Siguiendo a Pardo (2002) y Vargas et al (2007) las razones que propician el actual desdén por el legado industrial son:

1. Las ruinas de este período en ocasiones se asocian con efectos negativos, como la degradación ambiental, social y económica de un territorio.

2. Predomina un concepto de lo atractivo vinculado a la belleza, como principal criterio para catalogar a un bien como patrimonio.

3. La propia consideración temporal, efímera, que se otorga desde su origen a las instalaciones productivas.

4. La rápida obsolescencia física de las instalaciones y el desfase tecnológico, cada vez más acelerado, reduce los periodos de uso y provoca la destrucción de bastante material. 
Frente a este distanciamiento originario entre cultura e industria cabe preguntarse: ¿cuándo se produce el encuentro entre ambas? Sólo recientemente se estima la naturaleza cultural de lo industrial, en un proceso que se inicia en la década de los 60 del siglo XX, con el nacimiento de una nueva ciencia: la arqueología industrial, a la que se atribuye un papel relevante en la movilización reivindicativa de la sociedad en los lugares donde la desindustrialización es más patente. En España hasta prácticamente la década de los 90 se da una "falta de consideración de los valores culturales para las muestras materiales de la Revolución Industrial”' (Pardo, 2010:245).

Exponemos con mayor grado de detalle el modo en que se origina y hace efectivo el reconocimiento cultural, social e institucional y jurídico de los elementos fabriles del pasado.

\subsection{EL RECONOCIMIENTO CULTURAL Y SOCIAL DEL PATRIMONIO INDUSTRIAL}

Es en tiempos muy recientes cuando se toma verdadera conciencia de la dimensión cultural-patrimonial de los restos heredados de la industrialización (Pardo, 2002 y 2008 y Arocena, 2004). Además, el grado de sensibilización mostrado varía entre los distintos países europeos (Forner, 1991). Varios son los factores que contribuyen a la asimilación del pasado industrial como un elemento cultural: la sensibilidad social, la ampliación de los valores del patrimonio, su función regeneradora y el reconocimiento institucional y legal.

\section{La Sensibilidad Social.}

Los movimientos académicos y populares que tienen lugar en Gran Bretaña para salvar la Estación de Euston a principios de los años 60, así como la apertura del Iron Bridge Gorge Museum en 1968 constituyen puntos de referencia obligada en el proceso de valoración cultural de lo industrial (Forner, 1991). El apoyo ciudadano se acrecienta ante la inquietante sensación de velocidad impuesta por la rápida caducidad (Vicenti, 2007) de las técnicas y artefactos. Dicho respaldo resulta fundamental para operar este cambio de signo, pues "la madurez cívica y cultural de la sociedad que recibe dichos bienes es la mayor garantía para su respeto y conservación" (Forner, 1991:27). Sólo se pueden proteger tales elementos si todas las personas se dan cuenta de que el patrimonio se encuentra a su alrededor y si asumen como propia la responsabilidad de reconocerlo, cuidarlo y compartirlo; es decir si toman posesión de su propio patrimonio (Alfrey y Putnam, 1992). La conservación y la valoración no puede basarse únicamente en medidas legales y decisiones externas. Los propios habitantes deben concienciarse de dicho valor y conseguir su protección (Capel 1996b). En consecuencia, para superar concepciones negativas arraigadas es necesario crear o incrementar el conocimiento colectivo sobre el valor de estos testimonios (Forner, 1991; Capel 1996b y Pardo 2008) y fomentar la corresponsabilidad en su defensa entre diversos sectores: el sistema educativo, las sociedades cívico-culturales, las asociaciones empresariales y obreras (Forner, 1991).

Así pues, se hace patente que la mejor garantía de la conservación y valoración es que la sociedad adopte una actitud responsable y madura ante sus testimonios y 
expresiones culturales.

\section{La ampliación de los valores del patrimonio}

El aumento de la sensibilidad va en paralelo a la ampliación del significado de la cultura y el patrimonio, que se libera de su valor estético e incorpora otros conceptos más comprensivos.

El concepto de patrimonio es bastante reciente, surge en los siglos XVIII y XIX, período en el que se produce un cambio intelectual, social y económico que transforma radicalmente la sociedad (Casanelles, 2007). Su significado evoluciona a lo largo del tiempo (Vicenti, 2007) y, de una forma especialmente acelerada, en un escenario de cambios vertiginosos (Fernández, 2007). Sin embargo, sólo muy recientemente se amplía este concepto y se expande al campo de lo social (Pardo, 2008). Su transformación es impulsada con la Revolución Industrial, pues los cambios radicales en los modos de producción favorecen la generalización de la noción de patrimonio asociada a un valor histórico, y no únicamente al arte (Vicenti, 2007).

Más adelante, en el siglo XX, concurren otros factores que contribuyen a extender más el alcance del término patrimonial:

1. Por una parte, el concepto asimila dos nuevas características: una, la del objeto testimonio de una época, que pone el acento en el significado que tiene para la sociedad que lo fabrica; y dos, la del objeto de estudio, que amplía el campo de análisis más allá de las piezas de valor, a construcciones más ordinarias, fuentes de información cualitativa sobre los modos de vida (Casanelles, 1998 y 2001 y Vicenti, 2007). De este modo, el patrimonio histórico se desprende de una concepción esencialmente artística y como símbolo del pasado para dotarse de otra más vinculada con los intereses de la sociedad europea actual (Santacreu, 1991).

2. Por otra parte, el factor antigüedad, entendido como un valor positivo aplicado a los bienes materiales de eras pasadas se dota de un nuevo significado y se transforma en la "nueva antigüedad" (Casanelles 2007:60). La antigüedad entendida en clave decimonónica, junto con el concepto de obra de arte, conforma la noción de patrimonio aún vigente en la mente de muchas personas. Sin embargo, los cambios económicos y sociales sufridos, primero lineales y, a partir de la segunda guerra mundial, exponenciales transforman su sentido. La aceleración extrema conlleva la obsolescencia del mundo material de la industria que pasa a ser parte de la historia pasada y adquiere el valor de nueva antigüedad. Estos cambios conducen a otra gran revolución social que desemboca en la denominada sociedad post-industrial o post-moderna (Casanelles, 1998:59, 2001:34 y 2007), que se caracteriza porque:

"Padece cambios continuos que van haciendo variar en pocos años la tecnología, la cultura o los valores de la sociedad, las cosas se hacen viejas en poco tiempo. Y por ello, debido a la sociedad de consumo en la que vivimos, en la mayor parte de los casos, los objetos -como las 


\section{ideas- son desechados y olvidados" (Vicenti, 2007:9).}

El proceso de caducidad de los objetos se acorta de tal manera que pueden ser reemplazados, incluso antes de agotar su vida útil, simplemente por el hecho de haberse quedado desfasados (Vicenti, 2007). En consecuencia, la nueva antigüedad se erige en uno de los rasgos esenciales al definir los objetos patrimoniales. Tal velocidad de cambio hace que tengamos que incluir los objetos recientes, de la época industrial, como bienes patrimoniales, ya que conceptualmente son antiguos, aunque no lo sean en el tiempo. Pertenecen a otra era histórica; es decir, representan testimonios de un mundo próximo al nuestro en el tiempo, pero lejano en su concepción tecnológica (Casanelles y Fernández, 1994 y Casanelles, 1998 y 2001).

Asimismo, llamamos la atención sobre otros dos avances significativos en el concepto de patrimonio cultural por su especial incidencia en lo industrial:

- $\quad$ Por una parte, la incorporación de aspectos no sólo materiales, sino también inmateriales. El patrimonio cultural se concibe como aquél constituido por todos aquellos elementos y manifestaciones tangibles o intangibles producidas por las sociedades (Fernández y Ramos, 2004).

- Por otra parte, el reconocimiento expreso de la íntima relación existente entre el patrimonio y la identidad colectiva. Se llega a afirmar que contribuye "de forma singular a la configuración de su propia identidad colectiva" (Pardo, 2008:11) y se considera testimonio del modo en que una sociedad o cultura se relaciona con su ambiente (Fernández y Ramos, 2004).

Todos estos progresos amplían la noción preexistente de patrimonio cultural y respaldan de manera progresiva la incorporación de lo industrial a esta categoría. Así, una vez superado el criterio por el cual se seleccionan los bienes culturales por su atractivo, directamente ligado a la belleza, aumenta la variedad de contenidos y manifestaciones patrimoniales y surgen nuevas categorías (Vargas et al 2007), entre ellas la del patrimonio industrial.

La nueva tipología cultural se conforma poco a poco y genera debate entre los autores, que interpretan de diversa manera sus límites temáticos y cronológicos (Pardo 2008). Una definición referente es la que desarrolla la organización TICCIH en la Carta de Nizhny Tagil sobre Patrimonio Industrial en el 2003.

"El patrimonio industrial se compone de los restos de la cultura industrial que poseen un valor histórico, tecnológico, social, arquitectónico o científico. Estos restos consisten en edificios y maquinaria, talleres, molinos y fábricas, minas y sitios para procesar y refinar, almacenes y depósitos, lugares donde se genera, se transmite y se usa energía, medios de transporte y toda su infraestructura, así como los sitios donde se desarrollan las actividades sociales relacionadas con la industria, tales como la vivienda, el culto religioso o la educación. 
El período industrial de principal interés se extiende desde el principio de la Revolución industrial, la segunda mitad del siglo XVIII, hasta la actualidad, incluida. Si bien también se estudian sus raíces preindustriales y protoindustriales anteriores. Además, se recurre al estudio del trabajo y las técnicas laborales rodeadas de historia y tecnología." (TICCIH, 2003:1).

En la definición expuesta entran en juego tres dimensiones: su alcance temporal, los elementos que lo integran y el contexto en el que se desarrolla.

\section{Alcance temporal.}

Respecto a sus límites cronológicos, los autores coinciden mayoritariamente en sus orígenes, pero no en su momento final. El concepto se ha venido limitando al pasado, aunque progresivamente la doctrina lo amplía hasta fechas más recientes, e incluso llega a proponer expresamente la incorporación del presente. Ésta parece ser la visión que prevalezca, tras la conferencia internacional que auspicia la Organización Mundial del Turismo sobre patrimonio industrial, celebrada en Zabrze (Polonia, 2011). En sus conclusiones se aporta una definición de patrimonio industrial que integra, en condiciones de igualdad, a la industria viva con el resto de elementos que conforman el patrimonio industrial.

Los elementos que lo integran.

En este punto nos referimos, en primer lugar, a las temáticas y sectores que abarca; en segundo, a la naturaleza material e inmaterial de dichos elementos; y en tercero, a los valores que lo caracterizan.

Sobre las temáticas y los sectores, los autores se refieren generalmente a actividades del sector secundario. No obstante, debieran añadirse las del sector servicios, como parte integrante de la realidad socioeconómica del sistema productivo capitalista, especialmente si abarcamos también el momento actual.

En relación con la naturaleza tangible e intangible de los elementos del patrimonio industrial, existe una opinión muy extendida, coherente con la interpretación general del patrimonio cultural, de que lo integran no únicamente los bienes materiales, sino también los inmateriales, como la memoria oral, el patrimonio documental...

Respecto a los valores que lo caracterizan, se adecuan al nuevo concepto ampliado de cultura. Se superan los parámetros vigentes desde el siglo XVIII, la belleza y la antigüedad, porque no definen la esencia del patrimonio industrial. Los criterios que la Carta de Nizhny Tagil (TICCIH, 2003) considera para seleccionar los elementos industriales más valiosos son:

- La no excepcionalidad, que significa que su valor testimonial aumenta con la intensidad de uso. No obstante, también puede darse la singularidad en este patrimonio. Dicha particularidad suele residir, más que en el elemento en sí, en referencia al entorno natural y social en el que se implanta, en las relaciones que establece con este contexto y los efectos sobre él. 
- El valor como testimonio de la era industrial.

- El valor histórico-social.

- El valor tecnológico-científico.

- $\quad$ El valor estético, que a diferencia de épocas anteriores, deja de ser el criterio principal

- En los últimos tiempos se incorporan otros valores que completan y matizan los anteriores, como el de su integridad, su relación con el territorio, su autenticidad como espejo identitario y su valor de uso y didáctico (Pardo, 2008). Todos ellos deben considerarse en la selección de recursos de una oferta de turismo industrial basada en el pasado o en el presente.

\section{El patrimonio industrial y el contexto}

La actividad industrial se lleva a cabo en un entorno territorial y social, del que no puede desligarse. Una visión que entienda el patrimonio industrial como un conjunto de objetos aislados de su contexto territorial, social y cultural es limitada y necesita ser superada. Más allá de la lectura de los datos geográficos o descriptivos del recurso hay que atender a las realidades territoriales sobre las que se basan las actividades humanas. Porque el complejo fenómeno de la industrialización es el resultado de la interacción inevitable de las actividades humanas con el ambiente circundante y de la interconexión de múltiples factores. La industria es una consecuencia directa del uso que la sociedad hace del medio. Esta unidad e integración es necesaria para acceder a una explicación global de la industrialización del territorio (Edwards y Llurdés, 1996; Casanelles, 1998 y 2001; Arocena, 2004; Romero, 2006; González Pedraza, 2010; Álvarez, 2008 y 2010).

Tras explicar cómo surge la categoría patrimonial industrial nos detenemos en una implicación clara: el reconocimiento cultural debiera garantizar la preservación de los elementos de mayor significado técnico, social o territorial (Pardo, 2002). Sin embargo, el estatus de nuevo bien cultural y recurso para alentar un desarrollo sostenible a escala local y regional no parece ser suficiente para asegurar su valoración y protección. Su situación sigue siendo de fragilidad al estar constituido por elementos vulnerables y a veces incomprendidos (Álvarez, 2008 y 2010). La actuación de las administraciones es la que puede paliar tal precariedad. Su intervención encuentra justificación en el reconocimiento del papel tractor de los restos en la regeneración de los baldíos industriales.

\section{La capacidad regeneradora en las zonas desindustrializadas}

En los años 80 se desarrollan las primeras políticas regeneradoras en las regiones europeas más degradadas por el desmantelamiento de fábricas. La concepción negativa de estos residuos -vinculada a problemas económicos, sociales, medioambientales, etc.- invierte su signo al considerarlos factores clave para el desarrollo y reconversión; es decir, al concebirse como recursos con potencial económico (Alfrey y Putnam, 1992; Storm, 2008 y Benito, 2010). Pero, más allá de su consideración 
meramente económica, la activación de este legado supone la recuperación de la memoria colectiva y de la identidad, favoreciendo también el desarrollo socio-cultural (Arocena, 2004). La reutilización de espacios industriales abandonados forma parte de una agenda política y social que incorpora comportamientos económicos y sostenibles (Storm, 2008).

Esta nueva perspectiva consolida el estatus de los restos de la industrialización como bienes culturales, categoría que implica que se les debe otorgar un reconocimiento jurídico, una estructura administrativa y una política de protección de ámbito estatal o regional, según los casos (Benito, 2002).

\section{El reconocimiento institucional y legal}

Junto con la creciente sensibilidad social se produce una "atención institucional al problema de las ruinas industriales" (Benito y López, 2008:24), que salva de la extinción a muchos elementos. Vista la evolución social, nos adentramos ahora en la incorporación del patrimonio industrial al ámbito de los organismos internacionales y estatales. Reparemos, en primer lugar, en cómo se produce la asimilación desde organismos europeos y mundiales. Seguidamente nos centramos en el respaldo otorgado desde instancias estatales.

\section{El reconocimiento internacional}

- Se inicia en 1972 cuando la UNESCO proclama la "Convención sobre la Protección del Patrimonio Mundial, Cultural y Natural".

- En 1975 el Consejo de Europa promulga la "Carta Europea del Patrimonio Arquitectónico", un documento que proclama su valor como una herencia común europea. Esta declaración amplía la noción, en principio restringida a manifestaciones singulares y excepcionales, e incorpora el patrimonio vivo de los pueblos y ciudades, de aquéllos conjuntos arquitectónicos que definen la personalidad histórica en épocas recientes (Forner, 1991). De este modo se abre una puerta a obras vinculadas con el mundo productivo.

- En 1978 se constituye la organización mundial encargada del patrimonio industrial The International Committee for the Conservation of Industrial Monuments, TICCIH.

- En 1982 la UNESCO, en la "Declaración de México", propone un concepto amplio de cultura y de patrimonio cultural que también ampara expresiones de la cultura productiva.

- En 1985 se constituye en Luxemburgo, con la "Declaración Común", el Polo Europeo de Desarrollo. Es un proyecto piloto de cooperación internacional cuya finalidad es la de solucionar problemas derivados de la desindustrialización en Francia, Luxemburgo y Bélgica. Ésta y otras iniciativas posteriores similares obtienen fondos de financiación 
europeos: FEDER, INTERREG, URBAN, RECHAR; RESIDER, LEADER, PROPER o CULTURES, entre otros (Benito, 2002 y Vargas et al, 2007).

- $\quad$ El apoyo de la UNESCO al reconocer la dimensión cultural de los lugares industriales es fundamental para el cambio de percepción hacia estos bienes (Benito, 2002 y 2010; Pardo, 2008 y Storm, 2008). Su interés por el patrimonio industrial es reciente: hasta 1978 no se incluye un sitio industrial en la Lista del Patrimonio Mundial (la mina de sal polaca de Wieliczka). Y es a partir de 1992 cuando se establece una verdadera política de reconocimiento del valor patrimonial universal de los lugares, que da como resultado la sucesiva inscripción, a partir de 1994, de sitios industriales, como la Fábrica siderúrgica de Völklingen (Benito, 2002 y Pardo, 2008). Con la incorporación a la lista, la organización internacional los reconoce como elementos manifiestos de una cultura, pertenecientes a toda la humanidad y remarca su función de hitos en el planeta. A pesar de esta tardía intervención de la UNESCO, y del pequeño número de lugares industriales registrados en su lista (Llurdés, 1999 y Benito 2002), dicha admisión y las ulteriores en otros foros y organizaciones influyentes, se perfilan como las catalizadoras de su potencial como recurso (Benito 2010).

- En 1992 la Comunidad Internacional acepta el término paisaje cultural y lo incluye entre las definiciones de las "Directrices para la aplicación del Patrimonio Mundial, Cultural y Natural” de 1972 (Pérez y Parra, 2004). En el año 2000 el Consejo de Europa proclama el "Convenio Europeo del Paisaje", en el que reconoce su importante papel de interés general en los campos cultural, ecológico, medioambiental y social; asimismo, menciona su potencial para desarrollar la actividad económica y el empleo, así como su relación directa con la calidad de vida (Consejo de Europa, 2000). Estos reconocimientos velan por la integridad de las expresiones culturales ligadas a su origen geográfico y social y favorecen la interpretación contextual del patrimonio.

- Otro indicador que respalda su valor es la formulación de la "Carta de Nizhny Tagil sobre Patrimonio Industrial”, elaborada por el TICCIH en el 2003. Su preámbulo atribuye un valor humano universal a la evidencia material la industrialización.

- En el año 2004 se celebra en Polonia la $1^{\text {a }}$ Conferencia Internacional sobre Patrimonio Industrial como recurso para el Turismo y el Ocio. Bajo los auspicios de la Organización Mundial del Turismo (OMT), se formula la "Resolución de Zabzre", de la que emanan una serie de recomendaciones relacionadas con el uso coherente de las actividades turísticas, compatible con la preservación de los monumentos industriales para las generaciones actuales y futuras (Pardo, 2008). En abril 
del 2011 se celebra en la misma localidad polaca la $2^{\mathrm{a}}$ Conferencia sobre esta temática y en ella se establece un concepto ampliado de patrimonio industrial.

La figura 1 representa los hitos que acabamos de reseñar en relación con el reconocimiento internacional.

Figura 1. Reconocimiento del patrimonio cultural e industrial en Europa
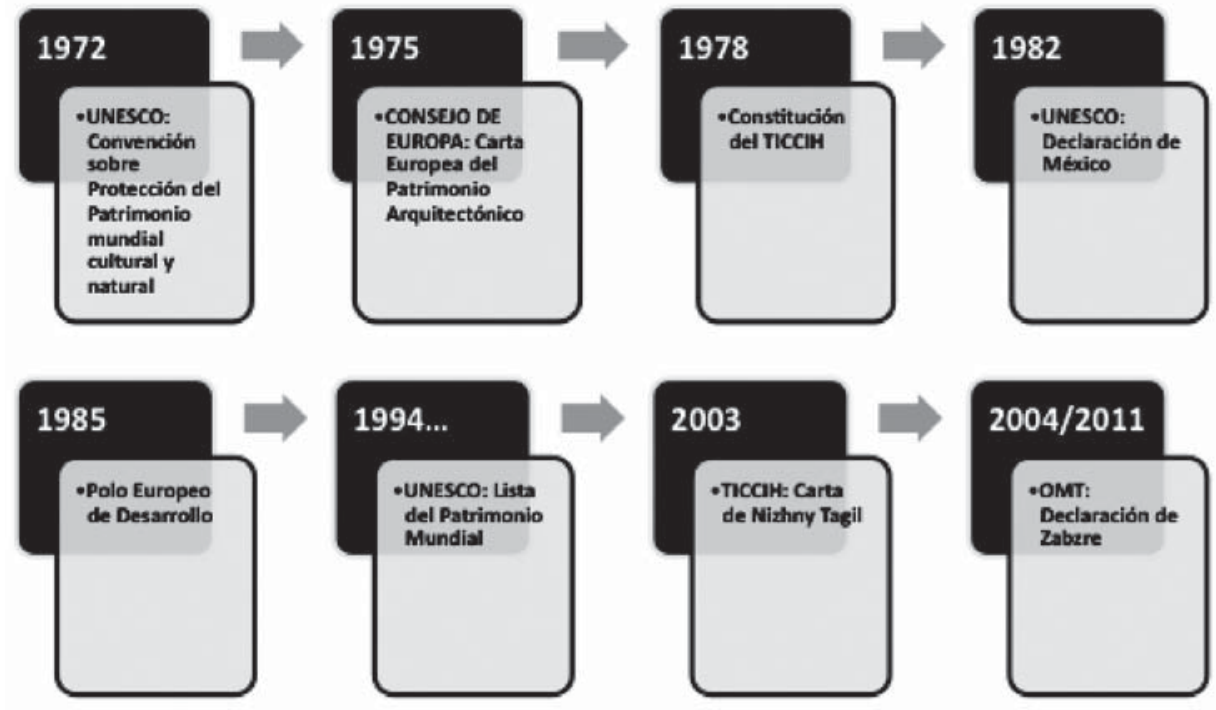

Fuente: elaboración propia

\section{El reconocimiento estatal}

En este punto se exponen las iniciativas desarrolladas desde el Ministerio de Cultura español, así como el marco normativo de ámbito estatal y autonómico que regulan la existencia y, en los casos más avanzados, también la protección del patrimonio industrial.

El reconocimiento más temprano viene dado por ley, ya que es en el 2001 cuando el Ministerio de Cultura formula un plan específico para la gestión de este patrimonio a nivel estatal. Analizamos primeramente la legislación y posteriormente las iniciativas ministeriales.

Marco normativo: La Constitución española recoge en su artículo 46 la obligación de los poderes públicos por velar y enriquecer el patrimonio histórico, cultural y artístico. Este precepto fundamental se desarrolla con la Ley 16/1985, que regula el Patrimonio Histórico Español. La norma no contempla de manera específica el concepto de patrimonio industrial en el artículo 1.2., en el que describe esta categoría. Destaca del texto legislativo la necesidad que impone de realizar inventarios de los bienes culturales y de establecer tipos y grados de protección. Los más relevantes deben clasificarse como Bienes de Interés Cultural (Pardo, 2008). 
El traspaso competencial en cultura favorece un desarrollo prolijo de normativa desde las CCAA (Pardo 2008). Algunas normas siguen el espíritu generalista de la ley de 1985, como por ejemplo la Ley 7/1990, de 3 de julio, de Patrimonio Cultural Vasco. Otras normas posteriores prevén el concepto específico de patrimonio industrial. La primera en hacerlo es la Ley 12/1998, de 21 de diciembre, de las Islas Baleares. A ella le siguen otras, como la ley cántabra o la madrileña, promulgadas en ese mismo año. Progresivamente las nuevas normas completan el concepto y aportan novedades. En este sentido cabe mencionar la Ley Asturiana 1/2001, de 6 de marzo, que explicita un régimen concreto para estos bienes (Pardo, 2008 y Álvarez, 2010) y la Ley 14/2007, de 26 de noviembre de Andalucía, que incorpora por vez primera el concepto de paisaje asociado a las actividades productivas, tecnológicas, fabriles o de la ingeniería (Sobrino, 2010).

Figura 2. Marco legal para el patrimonio industrial en España

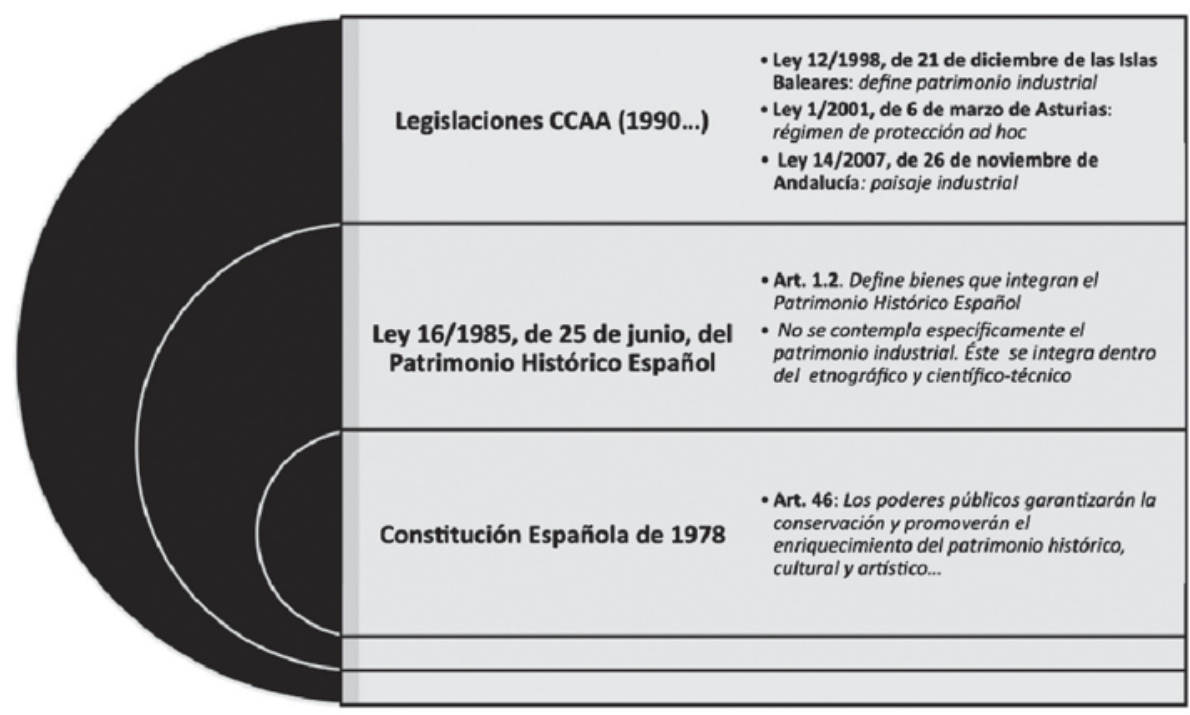

Fuente: elaboración propia

A pesar de los avances normativos experimentados, autores como Álvarez (2010) y González (2010) creen que es necesario actualizar el articulado que aún no reconoce de manera específica el patrimonio industrial, tal y como sucede en la ley estatal de 1985.

Iniciativas del Ministerio de Cultura: En el año 2001 se pone en marcha el "Plan Nacional de Patrimonio Industrial" gestionado por la Dirección General de Bellas Artes y Bienes Culturales, a través del Instituto de Patrimonio Histórico Español. Este patrimonio, por su propia especificidad, presenta un grave deterioro y está expuesto a desaparecer. Por ello, el Plan se concibe para salvaguardarlo a través de una serie de medidas que lo potencian como factor de desarrollo económico y social de escala local. Se formula a nivel estatal pero cuenta con el concurso de las comunida- 
des autónomas, que se responsabilizan de la selección de los cincuenta bienes sobre los que interviene el Plan. Su base legal es la Ley de Patrimonio Histórico de España de 1985 (Instituto de Patrimonio Histórico Español, 2001, Vicenti, 2007; Álvarez, 2008 y 2010 y Pardo, 2008).

Tras diez años de andadura el balance es positivo, supone que por primera vez se facilita el reconocimiento del patrimonio industrial como Bien Nacional. No obstante, diversos autores (Vicenti, 2007; Álvarez, 2010; Balboa, 2010; Incuna, 2010) señalan limitaciones, tenidas en consideración en la revisión del Plan que se inicia en el 2010.

En el 2007 se ratifica en España el "Convenio Europeo del Paisaje”, que se basa, por una parte, en la "Convención del Patrimonio Mundial de la UNESCO" (1972), ratificada por el Estado en 1992; y, por otra parte, en la "Convención Europea del Paisaje del Consejo de Europa" (2000), sancionada en el 2007. Fruto de estas confirmaciones el Instituto de Patrimonio Cultural Español establece una normativa sobre el Plan de Paisajes Culturales (Instituto de Patrimonio Cultural Español, n.d. y Álvarez, 2010).

Figura 3. Reconocimiento del patrimonio cultural e industrial en España

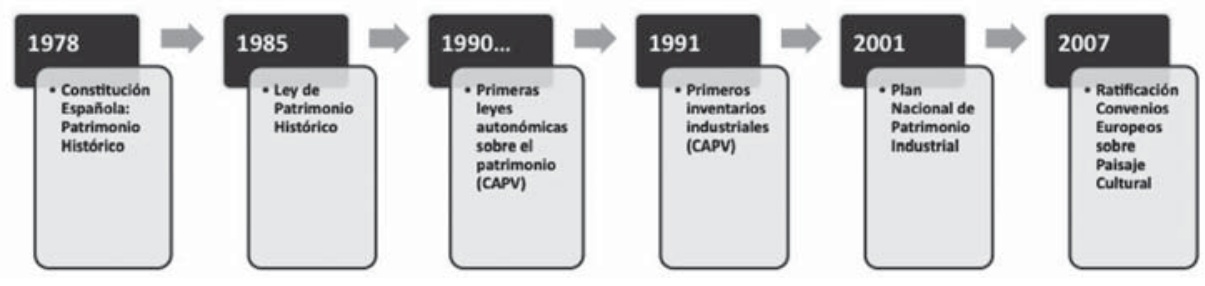

Fuente: elaboración propia

Todos los factores, sociales, institucionales y legales, descritos hasta aquí forjan de manera gradual la categoría cultural que hoy se asume sin ambages por la doctrina, que cada vez reconoce en mayor medida el valor de estos bienes culturales como testimonio de lo económico, tecnológico, etnológico y cultural de las sociedades históricas (González, 2010).

\section{LA INDUSTRIA VIVA DESDE LA PERSPECTIVA SOCIAL, PATRIMO- NIAL E INSTITUCIONAL}

Una vez explicados los motivos que originan el cambio de actitud por parte de la sociedad y la política hacia los bienes históricos de la industria, cabe realizar el mismo ejercicio con la industria viva.

\subsection{LA VALORACIÓN SOCIAL DE LA INDUSTRIA VIVA}

En relación con el interés social que la industria activa despierta se pueden diferenciar dos tiempos. Uno, se sitúa en los albores de la Revolución Industrial, mo- 
mento en que el mundo técnico despierta una curiosidad sin precedentes. La enciclopedia que Diderot y D'Alembert redactan entre 1751 y 1772 constituye una muestra brillante y significativa de dicha expectativa social (Sobry, 2001). Otro reflejo de la inquietud por conocer la cultura técnica son las visitas a empresa que se originan a finales del siglo XIX, como una forma elitista de conocimiento, en un momento en el que existen grandes expectativas con la novedad y el progreso (Capel, 1996; Sobry, 2001; Wagon, 2001; Morice, 2010a).

Conforme transcurren las dos primeras décadas del siglo XX, los avances técnicos se suceden a una velocidad cada vez mayor, pierden su carácter extraordinario y se produce un cambio de actitud, decae la curiosidad por conocer el modo en que se producen. A esto se suma el surgimiento del fenómeno del turismo de masas, asociado a la búsqueda de sol y playa, como un escape a la rutina laboral. Sin embargo, con el desarrollo de la sociedad postindustrial resurge la demanda: la deslocalización de los centros productivos en terceros países y la terciarización de las economías del mundo más desarrollado alejan al ciudadano occidental de las fábricas y resucita su interés (Capel, 1996b y Andreadakis y Davis, 1998). Concurren, además, un mayor nivel cultural y un cierto hastío de las formas tradicionales de vacaciones (Capel, 1996).

Este cambio de circunstancias renueva la atención hacia la actividad productiva. De este modo, conviven dos concepciones contrapuestas:

- Una actitud reacia hacia la industria como recurso atractivo para el ocio y el turismo. Especialmente desde los años 30 hasta la década de los 70, se mantiene que la industria ejerce un efecto repelente sobre cualquier actividad recreativa o turística $y$, en especial, para quienes habitan zonas altamente urbanizadas e industrializadas (Soyez, 1986). Esta idea aún pervive, porque el mundo de la empresa "parece en principio poco atractivo, estigmatizado por una mecanización generalizada, una repetición de tareas y duras condiciones de trabajo" (Morice, 2010a:14). Según este mismo autor, dicha falta de interés se debe también a la marcada huella agrícola que aún prevalece en Europa y que mantiene a la sociedad rural como referente de la edad de oro.

- Un interés creciente por la cultura técnica y científica actual. Esta inclinación emerge con la transformación socioeconómica que provoca la Tercera Revolución Industrial: "Cada vez que la sociedad industrial se transforma en sociedad moderna, el trabajo se convierte simultáneamente en un objeto de curiosidad turística" (MacCannell, 2003:9). Las empresas son -y para algunos siempre lo han sido- un foco de atracción para muchas personas interesadas en objetos técnicos (maquinaria), en arquitectura industrial, en técnicas de fabricación más o menos espectaculares, o en productos finales específicos, bien por su interés estético, su utilidad práctica o la posibilidad de degustarlos (Soyez, 1986). 
Más allá del conocimiento ceñido a los procesos o productos de una industria, hoy en día el modo de trabajar en un determinado lugar se entiende como un aspecto de la identidad regional y un componente importante de la calidad de vida a nivel local (MacCannell, 2003).

Observamos que, si bien existe una creciente sensibilidad social hacia la actividad productiva actual, el modo en que se genera difiere del interés por las ruinas industriales. En esta ocasión, es el cambio de modelo productivo, cada vez más alejado del sector secundario, el que prende la llama, lentamente. En el caso de las reliquias se trata de una respuesta ciudadana, respaldada por los académicos, ante un arrasamiento de elementos emblemáticos de una industria tecnológicamente superada.

Al mismo tiempo, existe una relación inversa entre ambas corrientes, puesto que la concepción de patrimonio que surge a partir de los años 50 supone un freno a la estimación social de las presentaciones industriales y técnicas, que en su origen dieciochesco y decimonónico se inscriben en un "contexto económico vivo, donde prevalece la actividad" y donde "no hay ruptura entre la presentación del objeto y su contexto de utilización” (Morice, 2010b:25). Sin embargo, conforme el objeto industrial se patrimonializa, pasa a integrar un universo prioritariamente desafectado. El renacer de la visita a empresa supone establecer nuevamente una "conexión con la realidad económica del momento" (Morice, 2010b:25).

Ayudaría a impulsar esta demanda erradicar el pensamiento de que hay que esperar a la muerte de un cierto número de empresas para que surja un interés cultural por ellas. Frente a la idea de que "cuando se cierra una fábrica se abre un museo", cabría aseverar que "cuando una empresa se abre (y se abre al público) se convierte en museo" (Wagon, 2001:51)

Por último, entendemos que, si bien el resurgir de la atención hacia la industria viva difiere con el interés que se origina con el Gran Tour del siglo XVIII (Sobry, 2001), ambos comparten su carácter novedoso, singular, la posibilidad de entrar en contacto con expresiones cotidianas de un territorio y de su comunidad (Morice, 2010b:26). Es decir, la oportunidad de vivir una experiencia auténtica.

Vista la repercusión social, analizamos a continuación la consideración patrimonial de los mundos del trabajo.

\subsection{LA CATEGORÍA PATRIMONIAL DE LA INDUSTRIA VIVA}

Los remanentes de la industria, impulsados en parte por las demandas ciudadanas, terminan por adscribirse a la categoría de bienes patrimoniales. Este hecho no se produce con la industria activa, huérfana de un reconocimiento cultural expreso y de un impulso social que lo reclame.

Sin embargo, entendemos justificado su carácter patrimonial. La primera enciclopedia contribuye a ampliar la noción de patrimonio, haciendo público un conocimiento hasta entonces privado. En consecuencia, el mundo del trabajo o el universo de la empresa dejan de considerarse como simples propiedades privadas y se reconoce el posible interés externo por conocerlos. La visibilidad promovida por las 
enciclopedias genera inquietud entre algunas organizaciones productivas, preocupadas por mantener en secreto sus técnicas de fabricación. Y para garantizar estos derechos empresariales se promulgan normas que protegen la propiedad industrial. No obstante, este derecho no debiera colisionar con el derecho a ver o acceder a la empresa, fundado en que una parte más o menos significativa de los procedimientos que aplica la industria, de los materiales que emplea o de los fenómenos físicos que permiten la producción son fruto de un trabajo colectivo, de una serie de investigaciones, de inventos, de innovaciones que superan ampliamente el universo de una empresa considerada como entidad aislada. Así, el deber de las empresas de asegurar su visibilidad social se justificaría por los beneficios que éstas obtienen de los recursos creados colectivamente. Por tanto, como consecuencia de reconocer que el éxito de una compañía siempre es producto -en distintos grados- de la sociedad y de la historia colectiva, se produciría una especie de patrimonialización pública que implicaría exponerse -con ciertos límites- a la mirada de extraños (Wagon, 2001).

La pertinencia de otorgar estatus patrimonial a la industria se aplica porque una vez que una actividad humana se valoriza, se legitima, se hace comprensible (Wagon, 2001). Esta idea concuerda con la noción aperturista de patrimonio como una "construcción social" (Homobono, 2008:61) que no se reduce a sus recursos patrimoniales del pasado, es un fenómeno vivo, en permanente cambio y construcción. En efecto, su carácter vivo es relativo y puede fluctuar con el transcurso del tiempo (Cuvelier, 2001).

Excluir a la industria viva de la categoría patrimonial ralentiza su consideración social como "lugares dignos de interés para un público cada vez más curioso por conocer bien todo lo que configura la singularidad de un territorio" (Morice, 2010b:20).

Seguidamente se analizan tres posibles caminos que permitirían elevar a cultural la actividad industrial actual: su consideración como patrimonio contemporáneo, como patrimonio inmaterial o como patrimonio industrial reconsiderando su alcance temporal

\section{El patrimonio contemporáneo}

Una de las posibles denominaciones patrimoniales dentro de las cuales pudiera encajar esta realidad de cara a su apreciación como bien cultural y social es la de patrimonio contemporáneo.

Este concepto es impulsado por la Fundación DOCOMOMO (Documentation and Conservation of buildings, sites and neighbourhoods of the Modern Movement), creada en 1990 y con representación en la península ibérica desde 1993. Su finalidad originaria es "estudiar y documentar la arquitectura del movimiento moderno con el fin de lograr su reconocimiento como parte de nuestra cultura del siglo $X X$, su protección patrimonial y conservación" (Fundación DOCOMOMO Ibérico, 2011).

La UNESCO oficializa la colaboración con esta fundación en aplicación del capítulo II de las directrices sobre las relaciones de la UNESCO con las ONG aprobadas en 1995 y revisadas en 2001 (UNESCO, 2008). Por tanto, a pesar de no existir una definición explícita sobre este tipo de patrimonio, sí existe un reconocimiento tácito por parte de la UNESCO. 
Esta concepción resulta interesante porque permite el encaje de la arquitectura de empresas y organizaciones en funcionamiento. No obstante, resulta restringido porque al centrarse exclusivamente en los bienes inmuebles no permite la consideración de los elementos muebles e inmateriales, también manifestaciones de la cultura productiva actual.

\section{El patrimonio inmaterial}

Otra posible acepción es la del patrimonio inmaterial, categoría reconocida oficialmente desde el 2003 por la UNESCO.

Hasta los años 50 el patrimonio se restringe a la dimensión material de una parte de la cultura, representativa de las élites sociales que ostentan el poder políticoreligioso o económico, o a los gustos e ideales estéticos de la sociedad occidental (Carrera, n.d.). Sin embargo, en los últimos tiempos cobra fuerza la idea de que es necesario preservar y difundir el patrimonio cultural de cada pueblo; además, se suma la convicción de que el patrimonio no debe hacer una referencia exclusiva al pasado y a lo monumental, sino que, del mismo modo, debe referirse al valor fundamental de todo aquello que se relacione con la vida cotidiana, el presente y el futuro de los pueblos donde se haya creado y se siga creando (FEDIPA, n.d.). Se entiende que "un concepto moderno de patrimonio cultural incluye no sólo los monumentos y manifestaciones del pasado..., sino también lo que se llama patrimonio vivo" (Fernández y Ramos, 2004:117). Es decir, se reclama un patrimonio que se vincule con el concepto antropológico de la cultura (Carrera, 2004, citado por Carrera, n.d). Sobre la ampliación del significado cultural y su interpretación, Bouchenaki (2007) revela que a partir de los años 90 se intensifica la búsqueda del significado de las expresiones culturales y surge la necesidad de identificar los usos sociales y los sistemas de creencias.

Como consecuencia de estas tendencias ven la luz una serie de conceptos que designan el patrimonio relacionado con hechos vivos: patrimonio oral, patrimonio cultural viviente, patrimonio intangible. Paulatinamente estas definiciones se reconocen a través de diversos documentos de la $\mathrm{UNESCO}^{1}$ que culminan con la publicación de la "Convención para la Salvaguardia del Patrimonio Cultural Inmaterial" en el 2003. (Bouchenaki, 2007; Carrera, n.d. y FEDIPA, n.d) y el "Kit sobre el patrimonio cultural inmaterial" en el 2009, instrumento pedagógico para el fomento y garantía de la efectiva comprensión de la Convención de 2003.

La UNESCO define en el artículo 2.1. de la Convención del 2003 el concepto de patrimonio inmaterial:

"Se entiende por patrimonio cultural inmaterial los usos, representaciones, expresiones, conocimientos y técnicas -junto con los instrumentos, objetos, artefactos y espacios culturales que les son

1 La Recomendación de la UNESCO sobre la salvaguardia de la cultura tradicional y popular de 1989, la Declaración Universal de la UNESCO sobre la Diversidad Cultural de 2001 y la Declaración de Estambul de 2002 . 
inherentes- que las comunidades, los grupos y en algunos casos los individuos reconozcan como parte integrante de su patrimonio cultural. Este patrimonio cultural inmaterial, que se transmite de generación en generación, es recreado constantemente por las comunidades y grupos en función de su entorno, su interacción con la naturaleza y su historia, infundiéndoles un sentimiento de identidad y continuidad y contribuyendo así a promover el respeto de la diversidad cultural y la creatividad humana" (UNESCO, 2003:2).

Se trata de un concepto difuso; por ello, la propia Convención, en su artículo 2.2., propone una serie de ámbitos o dominios en los que se manifiesta de manera particular (UNESCO, 2003):

- Tradiciones y expresiones orales, incluido el idioma

- Artes del espectáculo

- Usos sociales, rituales y actos festivos

- Conocimientos y usos relacionados con la naturaleza y el universo

- Técnicas artesanales tradicionales

Esta lista es abierta, en términos de la propia UNESCO (2009b). Por una parte, cada dominio no se limita a una única una expresión cultural y, a su vez, ésta puede incluir elementos de varios dominios. Así, los límites entre los dominios son fluidos y a menudo varían entre las distintas comunidades.

La actividad industrial pudiera verse reflejada parcialmente a través del dominio de las técnicas artesanales y tradicionales. Un ejemplo lo encontramos en Francia, donde se ha calificado bajo esta categoría el sistema de Maestros del Arte, que reconoce a docenas de artesanos ejemplares en campos tan diversos como la fabricación de instrumentos musicales, trabajos textiles y encuadernación. La finalidad de este sistema es apoyar la transmisión de su conocimiento y habilidades a otras personas (2009b).

Si bien el concepto que formula la UNESCO (2003) en su Convención es amplio, la limitación es hermenéutica, ya que el campo de acción se concreta en una proposición de dominios que prácticamente no se han dotado de un contenido industrial. Comprobamos cómo la única actividad productiva contemplada ha sido la de los maestros del arte en Francia, cuya labor es básicamente artesanal. Parece que la vocación de este patrimonio es la de acoger primordialmente manifestaciones más tradicionales y, aunque expresamente se reconoce el valor de lo vivo, no se ha desarrollado una dirección clara que ampare la actividad productiva moderna.

\section{La ampliación del límite cronológico del patrimonio industrial}

Hasta tiempos recientes, la doctrina mayoritaria española y de terceros países refiere el patrimonio industrial, prácticamente de manera unánime, a un tiempo pretérito. Esta percepción limita la integración de las organizaciones actuales bajo este concepto.

Sin embargo, gradualmente se atisba una mayor amplitud de miras. Algún autor español ya considera abiertamente que "el patrimonio industrial puede estar vivo, 
en funcionamiento todavía o en peligro de desaparición" (Álvarez, 2008:6). Esta extensión del término patrimonial coincide plenamente con la asumida por otros autores franceses que adoptan una visión global y comprenden el patrimonio antiguo, pero también otro contemporáneo, llamado "patrimonio vivo", que consiste en la visita a empresas en actividad y que se contrapone al "patrimonio industrialmente muerto", como las ruinas industriales (Cuvelier, 2001:27). Wagnon (2001), asume que las empresas son un recurso básico de la oferta de turismo industrial, y Sobry y Cuvelier (2001), creen que la curiosidad por la actividad económica de hoy se valoriza e institucionaliza progresivamente. Afirma Morice (2010a) que la dimensión viva de este patrimonio es la que puede dinamizar el desarrollo del turismo industrial en mayor grado, reconociendo de este modo su potencial.

La declaración más contundente al respecto se produce en la Conferencia celebrada en Zabrze (Polonia) en abril del 2011 sobre los usos turísticos y de ocio del Patrimonio Industrial. En las conclusiones de dicho encuentro se define el patrimonio industrial del siguiente modo:

"El patrimonio industrial está representado por una serie de bienes relacionados con las actividades productivas humanas, tales como los monumentos y estructuras industriales y tecnológicos, la industria viva de cualquier clase, así como el patrimonio intangible" (Ministry of Sport and Tourism of the Republic of Poland, 2011:1).

En esta definición la industria viva se integra en condiciones de igualdad con el resto de elementos que conforman el patrimonio industrial.

Ésta parece ser la vía más oportuna y natural para estimar culturalmente a la industria contemporánea. Veamos a continuación la protección otorgada por las administraciones.

\subsection{EL RECONOCIMIENTO INSTITUCIONAL Y LEGAL}

Al igual que ocurre con la valoración cultural, tampoco existe una dinámica oficial que proteja y dignifique la actividad productiva como bien cultural. El único ejemplo identificado que otorga un estatus institucional o legal al mundo productivo actual es el promovido por los poderes públicos de Francia, que desarrollan un sello que reconoce a las empresas de patrimonio vivo que acrediten unos valores vinculados al origen francés de la organización y que se reflejan en sus modos de trabajo y en su oferta. Toda la información que se presenta a continuación es obtenida de l'Institut Supérieur des Métiers (2009).

Se trata de una iniciativa puesta en marcha por el Ministerio de Economía, Finanzas e Industria que pretende distinguir a las empresas francesas que trabajan de modo artesanal y a las industrias excelentes. El sello se concede por un período de cinco años y reúne a empresas con altas prestaciones en su trabajo y productos.

La marca se crea por virtud de la Ley $N^{\circ} 2005-882$ de 2 de agosto de 2005 para las pequeñas y medianas empresas y su concesión se regula a través del Decreto de 23 
de mayo del 2006. Según el artículo 23 de la ley, se otorga a toda empresa que ostente un patrimonio económico, que se componga, en particular, de unos conocimientos técnicos raros, de renombre o ancestrales, que dependan del dominio de técnicas tradicionales o de la alta tecnicidad y que se circunscriban a un territorio.

La concesión de la marca significa un reconocimiento a las empresas por parte del Estado, así como un apoyo operativo a su desarrollo, que se traduce en: facilitar su mediación a una escala nacional e internacional, crear y aprovechar las oportunidades internacionales de negocios, incitarles a innovar, favorecer su crecimiento, asegurar el desarrollo de empleo y ayudar a su promoción. Además, las organizaciones que participan disfrutan de incentivos fiscales por admitir personal en prácticas y por creación de nuevos productos.

Este marchamo representa una garantía de calidad tanto para las empresas, como para los consumidores, clientes y prescriptores que deseen la intervención de un profesional reconocido por el respeto a la profesión y por su aptitud excepcional.

Los valores que identifican a las empresas participantes son: la adaptabilidad, la capacidad de reacción, la innovación y la pasión por el oficio. Independientemente de su tamaño, notoriedad o especialización, en conjunto velan por un tesoro, que es el patrimonio manufacturero francés.

Estas organizaciones mantienen su actividad productiva en Francia, en sectores de un elevado valor añadido. La mayoría tienen presencia en mercados internacionales y exportan los conocimientos técnicos emblemáticos del país. Representan el espíritu del saber técnico hecho en Francia y forjan su identidad económica y cultural. Con ello se contribuye a la creación de empleo fijo y a la no deslocalización de la actividad productiva.

Como depositarias de un patrimonio, numerosas empresas de patrimonio vivo proponen al público descubrir su historia, su oficio, sus realizaciones organizando visitas a sus instalaciones. Esta iniciativa, inédita en otros países europeos, representa una buena práctica que fomenta, no sólo la imagen de las empresas beneficiarias, sino la del país en su conjunto.

\section{CONCLUSIONES}

La ampliación del concepto de patrimonio cultural, en gran parte por los propios cambios que impone la Revolución Industrial, desembocan en la creación de una nueva categoría: el patrimonio industrial. Su origen tiene un tinte marcadamente social y vinculado en exclusiva a las reliquias en inminente riesgo de desaparición. La aplicación del estatus cultural se ve reforzada por el cambio de perspectiva de los poderes públicos, que atisban su poder regenerador y paliativo de las maltrechas economías, desprovistas de su tejido industrial. Este hecho respalda la progresiva institucionalización de su reconocimiento, a través de declaraciones y normas. 
Si la secuencia resulta bastante clara para el caso de los restos industriales, no ocurre lo mismo con las organizaciones activas de hoy. En su caso, el reconocimiento social es tibio y no responde a un ímpetu social, no se ve la urgencia, ni siquiera la necesidad de valorar y proteger a la industria viva como una manifestación cultural, representativa de la identidad de un territorio y sus gentes. Las consecuencias son manifiestas: su valoración cultural es débil, si bien en los últimos años encuentra cada vez más apoyos y llega a incorporarse expresamente en la categoría de patrimonio industrial con la declaración de la Conferencia de Zabrze (2011). Así, no es de extrañar que el respaldo oficial es hoy en día precario, salvo en el caso de Francia, que crea vía ley un sello para reconocer a las empresas de patrimonio vivo.

Observamos la notable diferencia que media entre el estatus logrado por los restos productivos y por la industria viva. En nuestra opinión, tales diferencias, originadas en gran parte por el propio transcurso de los acontecimientos, no cuentan con un argumento conceptual para perpetuarse. Es decir, entendemos que debiera igualarse la consideración y protección prestada a ambos recursos. Esta demanda se apoya en la naturaleza, bastante similar, de la industria del ayer y la actual. La tabla 2 aporta una síntesis de las similitudes y las diferencias existentes entre ambas.

Tabla 2. Aspectos comunes y diferentes de la industria del pasado y la actual.

\begin{tabular}{|c|c|c|}
\hline Característica & $\begin{array}{l}\text { Patrimonio Industrial } \\
\text { histórico }\end{array}$ & Industria viva \\
\hline Ámbito temporal & $\begin{array}{l}\text { Desde el inicio de la } \\
\text { Revolución Industrial hasta } \\
\text { que la tecnología cae en } \\
\text { desuso }\end{array}$ & Presente \\
\hline Tecnología empleada & Obsoleta & Actual \\
\hline Temáticas & $\begin{array}{l}\text { Relacionadas con las áreas } \\
\text { productivas }\end{array}$ & $\begin{array}{l}\text { Relacionadas con las áreas } \\
\text { productivas } \\
\text { Una mayor presencia de servicios } \\
\text { por la terciarización social }\end{array}$ \\
\hline Elementos & Materiales e inmateriales & Materiales e inmateriales \\
\hline Valores & $\begin{array}{l}\text { Histórico } \\
\text { Arquitectónico } \\
\text { De conjunto } \\
\text { Territorial } \\
\text { Iconográfico } \\
\text { De conservación } \\
\text { De uso } \\
\text { Didáctico }\end{array}$ & $\begin{array}{l}\text { Histórico } \\
\text { Arquitectónico } \\
\text { De conjunto } \\
\text { Territorial } \\
\text { Iconográfico } \\
\text { De conservación } \\
\text { De uso } \\
\text { Didáctico }\end{array}$ \\
\hline
\end{tabular}

Fuente: elaboración propia. 
Como se aprecia en la tabla ambos recursos poseen bastantes características en común. Sus temáticas son similares, se centran en la esencia del sistema capitalista: el modo en que la sociedad produce bienes y servicios, con las consecuencias sociales que ello supone. Por la terciarización de la economía postmoderna es lógico que en la actualidad se incorporen los servicios en mayor proporción que en épocas pasadas. Asimismo, los elementos contemplados, materiales e inmateriales, coinciden en ambos casos. Y, por último, la industria como manifestación cultural, sea de ayer o de hoy refleja unos valores análogos: tan importante es la historia de algo pretérito, como su trayectoria hasta la actualidad; su importancia arquitectónica tampoco varía por el momento de su construcción, especialmente para este tipo de elementos, emancipados de los valores estéticos; la conveniencia de entender la actividad como parte de una dinámica socioeconómica que transforma el territorio evidencia la importancia que en los dos momentos tiene el valor iconográfico, de conjunto y el territorial. Y en su capacidad para transmitir la esencia de este proceso radican sus valores de uso y didáctico. Por último, el criterio de conservación es claro para el patrimonio pretérito y debe entenderse como un incentivo de la salvaguarda en vida de los bienes actuales. Podemos concluir que los factores que otorgan valía a la industria apenas cambian por el hecho de pertenecer a otro tiempo o al actual.

La diferencia más significativa entre ambos es la tecnología que se emplea, obsoleta en el caso del patrimonio industrial, y actual en las organizaciones activas. Si bien también es distinto el alcance temporal de uno y otro, entendemos que este criterio se disipa en un escenario gobernado por la velocidad extrema que los avances técnicos provocan. Así, el concepto de nueva antigüedad desplaza el centro de atención del transcurso objetivo del tiempo a la superación tecnológica.

Bajo nuestro punto de vista, la diferencia tecnológica no es un argumento que justifique el diferente tratamiento que en este momento persiste. Además, entendemos que la privación de este estatus a la industria viva supone una serie de consecuencias negativas, que repercuten en la concepción y desarrollo de una oferta integral de turismo industrial:

- En primer lugar, al no valorarse, se mantiene el actual desconocimiento y falta de sensibilidad social hacia la industria de hoy. Según los criterios aún defendidos por parte de la doctrina, que consideran que el patrimonio industrial se compone de testimonios del pasado industrial, y vista la acelerada evolución tecnológica, lo que hoy es puntero en un breve lapso de tiempo pasará a formar parte del pasado y a merecer consideración y protección.

- En segundo, dentro de las organizaciones productivas tampoco se da una conducta que promueva la valoración y salvaguarda de su cultura industrial, ni pasada ni presente. Esta falta de sensibilidad incide directamente en el riesgo de desaparición a que estos elementos se verán abocados una vez su tecnología sea suplantada por otra más sofisticada. 
- En tercer lugar, la destrucción de elementos tan recientes supone una pérdida de identidad sobre la que en muchas ocasiones no existe una conciencia clara al no existir todavía una distancia temporal suficiente que ayude a asimilar la importancia de lo que se deja atrás. Éste es un efecto directo de la implantación de la nueva antigüedad.

- Y, en cuarto lugar, la pérdida en vida de la actividad productiva disuelve nuestra identidad. Ya nos hemos referido a que la particularidad de lo productivo se debe no a las máquinas o a las técnicas en sí, sino mayoritariamente al modo en que se implantan en el contexto, así como a los efectos que se derivan. Por este motivo, el no valorar, cuidar, proteger la actividad productiva, supone su más que probable destrucción, una vez que su tecnología quede desfasada.

Tras el análisis realizado estamos en condiciones de confirmar la hipótesis que nos planteamos en la introducción. La falta de valoración o la persistencia de las desigualdades en la consideración, tanto social como cultural e institucional, socava la conceptualización integradora del turismo industrial y su posterior desarrollo. Si los recursos sobre los que se apoya no gozan de un estatus similar, difícilmente se podrá articular una oferta realmente representativa de la idiosincrasia industrial tradicional y actual.

Bajo nuestra mirada, la vía más propicia para activar el proceso de reconocimiento cultural y asimilar la protección pública existente es la extensión del concepto de patrimonio industrial hasta el presente para dar cabida a la actividad productiva de nuestros días. De las tres posibilidades conceptuales planteadas ésta resultaría la opción más natural, visto el corpus común existente entre los restos productivos y la industria viva. Sería interesante incorporar de una manera expresa la filosofía y finalidad del patrimonio contemporáneo y del patrimonio inmaterial a esta noción ampliada de patrimonio industrial, para completar su alcance y adecuarlo a las circunstancias actuales. Existiendo una noción ya consolidada de patrimonio industrial, es más razonable sugerir una evolución, una actualización de su significado para hacerlo más comprensivo. Esta nueva interpretación ayudaría a fomentar el cuidado de la industria desde el momento en que entra en funcionamiento. Con esta decisión se acabaría con una división de lo que entendemos son dos manifestaciones complementarias de la misma realidad: la industrialización en la era capitalista, en la que aún nos encontramos.

\section{BIBLIOGRAFÍA}

Alfrey J. y Putnam T. (1992): The Industrial Heritage, Managing resources and uses, Londres, Routledge.

Álvarez Areces, M. A. (2001): "Patrimonio industrial, identidad cultural y sostenibilidad" en M. A. Álvarez Areces (ed.) Arqueología Industrial, Patrimonio y Turismo Cultural, Gijón, CICEES, pp.13-31. 
- (2008): "Patrimonio industrial, Un futuro para el pasado desde la visión europea", Apuntes, 21(1): 6-25.

- (2010): "Patrimonio industrial en España", I Jornada de Expertos en Patrimonio Industrial, Presente y perspectivas de futuro, La Robla/Sabero 16 de octubre. Recuperado el 1 de febrero de 2011 de http.//www.fhvl.es/fhvl/images/content/ pdfs/MIGUEL_ANGEL_ARECES.pdf

Andreadakis, R. y Davis J. A. (1998): "Industrial Heritage Tourism at the Bingham Canyon Copper Mine", Journal of Travel Research, Winter, 85-89.

Arocena, F, (2004): "Patrimonio industrial, turismo cultural y desarrollo. El potencial del ferrocarril en el barrio Penarol de Montevideo", Cuadernos Del CLAEH, 27(88): 65-71.

Balboa, J. A. (2010): "Una visión optimista del patrimonio industrial", I Jornada de Expertos en Patrimonio Industrial, Presente y perspectivas de futuro. La Robla/ Sabero 16 de octubre, Recuperado el 1 de febrero de 2011 de http.//www.fhvl.es/ fhvl/images/content/pdfs/J_A_BALBOA.pdf

Benito del Pozo, P. (2002): "Patrimonio Industrial y Cultura del Territorio", Boletín de la $A, G, E, 34,213-227$.

_- (2010): "El sentido del patrimonio industrial, conquistas y retos", I Jornada de Expertos en Patrimonio Industrial, Presente y perspectivas de futuro, La Robla/ Sabero 16 de octubre, Recuperado el 1 de febrero de 2011 de http.//www.fhvl.es/ fhvl/images/content/pdfs/PAZ_BENITO_DEL_POZO.pdf

Benito del Pozo, P. y López A. (2008): "Patrimonio industrial y nuevas perspectivas funcionales para las ciudades en reestructuración”, Estudios Geográficos, LXIX, 264, 23-50.

Bouchenaki, M. (2007): "A major advance towards a holistic approach to heritage conservation. The 2003 Intangible Heritage Convention", International Journal of Intangible Heritage, 2, 106-109.

Capel, H, (1996a): "El turismo industrial y el patrimonio de la electricidad", Actas de las I Jornadas sobre catalogación del Patrimonio Histórico, Sevilla, Instituto Andaluz del Patrimonio Histórico, Recuperado el 20 de enero de 2011 de http.// www.ub.edu/geocrit/sv-14.htm

-_ (1996b): "La rehabilitación y el uso del patrimonio histórico industrial", Documents d'Anàlisi Geogràfica, 29:9-50.

Carrera, G, (n.d.) El patrimonio inmaterial o intangible, recuperado el 22 de febrero de 2011 de http./www.juntadeandalucia.es/cultura/iaph/html/portal/com/bin/portal/Tematicas/InformacionPH/Documentacion/CriteriosMetodologias/index. html/1141631388722_el_patrimonio_inmaterial_o_intangible.pdf

Casanelles, E. y Fernández, M. (1994): "Un modelo para trabajar el patrimonio industrial. La propuesta del Museu de la Ciencia i de la Técnica de Catalunya”, ÍBER Didáctica de las Ciencias Sociales, Geografía e Historia, 2:51-59.

Casanelles, E. (1998): "Recuperación y uso del patrimonio industrial", Cuadernos del CLAEH, 29 (88): 57-64. 
- (2001): "El patrimonio industrial" en M. A. Areces (ed.) Arqueología Industrial, Patrimonio y Turismo Cultural, Gijón, CICEES, pp. 33-40.

- (2007): "Nuevo concepto de Patrimonio Industrial, evolución de su valoración, significado y rentabilidad en el contexto internacional", Bienes Culturales, Revista del Instituto de Patrimonio Histórico, 7: 59-70. Recuperado el 24 de febrero de 2011 de http.//www.calameo.com/read/0000753353edaf669f1f9

Consejo de Europa, (1975): Carta Europea del Patrimonio Arquitectónico. Recuperado el 5 de marzo de 2011 de http.//www.mcu.es/patrimonio/docs/MC/IPHE/ Biblioteca/AMSTERDA.pdf

- (2000): Convenio Europeo del Paisaje. Recuperado el 5 de marzo de 2011 de http.// www.mma.es/secciones/desarrollo_territorial/paisaje_dt/convenio_paisaje/pdf/ CONVENIO_EUROPEO_PAISAJE_Web.pdf

Cuvelier, P, (2001): "Le tourisme industriel, tentative de clarification conceptuelle" en M. Damien, y C. Sobry (eds.) Le tourisme industriel, le tourisme du savoir faire? París, L'Harmattan, pp. 15-28.

Edwards, J. A. y Coit, J. (1996): "Mines and quarries. Industrial heritage tourism", Annals of Tourism Research, 23(2): 341-363.

Fedipa, (n.d.): Carnaval Ayacuchano Patrimonio cultural de la nación. Patrimonio vivo. Recuperado el 13 de enero del 2011 de http.//fedipa2008.blogspot.com/

Fernández, G. y Ramos, A. (2004): "Patrimonio industrial, turismo cultural y rutas turísticas para un desarrollo local sustentable", Caminhos de Geografia, 8(11): 114-129.

Fernández-Baca, R. (2007): "Reflexiones sobre el Patrimonio Industrial", Bienes Culturales, Revista del Instituto de Patrimonio Histórico, 7: 53-57. Recuperado el 24 de febrero de 2011 de http.//www.calameo.com/read/0000753353edaf669f1f9

Forner, S. (1991): "Arqueología Industrial, concepto, teoría y métodos", C. Ramos et al (eds.) Arqueología Industrial, Notas para un debate, Málaga, Universidad de Málaga, pp. 23-38.

González, J. A. (2010) (coord.) "Conclusiones", I Jornada de Expertos en Patrimonio Industrial. Presente y perspectivas de futuro", La Robla/Sabero 16 de octubre. Recuperado el 1 de febrero de 2011 de http.//www.fhvl.es/fhvl/images/content/pdfs/ CONCLUSIONES.pdf

Homobonno, J. I. (2008): "Del patrimonio cultural al industrial, una mirada socioantropológica" en X. Pereiro, S. Prado y H. Takenara (coords.) Patrimonios culturales, educación e interpretación. Cruzando límites y produciendo alternativas, Donostia-San Sebastián, Ankulegi Antropologia Elkartea, pp. 56-74.

Hospers, G. (2002): Industrial Heritage Tourism and Regional Restructuring in the European Union, European Planning Studies, 10 (3): 397-404.

Instituto del Patrimonio Cultural de España (2000): Plan del patrimonio Industrial, Recuperado el 22 de febrero de 2011 de http.//www.mcu.es/patrimonio/MC/ IPHE/PlanesNac/PlanIndustrial/PatrimonioIndustrial.html 
L'Institut Supérieur des Métiers (2009): Entreprise du Patrimoine Vivant. Recuperado el 5 de marzo de http.//www.patrimoine-vivant.com/label/decouvrir_le_label/ el_etatun_lab

Llurdés, J.C. (1999): "Patrimonio industrial y Patrimonio de la Humanidad. El ejemplo de las colonias textiles catalanas. Potencialidades turísticas y algunas reflexiones", Boletín de la A. G.E., 28, 147-160.

Morice, J.R. (2006): "La visite d'entreprise en Europe. Un champ à explorer", Les Cahiers Espaces, Visite d'entreprise, 92: 10-15.

_- (2010a): "Por un reconocimiento de la visita de empresa en Europa" en A. Zárate y J.R. Morice (dirs.) Visita de empresa y turismo. Contexto español y perspectivas europeas, Cámara de Comercio de Industria de Toledo, Toledo, pp.12-16.

-_ (2010b): "Una conexión entre los mundos laborales del pasado y del futuro, la visita de empresa" en A. Zárate y J.R. Morice (dirs.) Visita de empresa y turismo, Contexto español y perspectivas europeas, Cámara de Comercio de Industria de Toledo, Toledo, pp. 20-31.

Pardo, C. J. (2002): Rutas y lugares de patrimonio industrial en Europa, consideraciones sobre su aprovechamiento turístico, Espacio, Tiempo y Forma, Serie VI, Geografía, 154: 69-94.

-_ (2008): Turismo y Patrimonio Industrial, Madrid, Editorial Síntesis.

-_ (2010): El patrimonio industrial en España, análisis turístico y significado territorial de algunos proyectos de recuperación, Boletín de la Asociación de Geógrafos Españoles, 53: 239-264.

Pérez, L. y Parra, C. (2004) Paisajes culturales, el parque patrimonial como instrumento de revalorización y revitalización del territorio, Theoría, 13(9): 9-24.

Romero, E. M. (2006) Recursos para el turismo industrial en la provincia de Huelva, Universidad Internacional de Andalucía. Recuperado el 25 de enero de 2011 de http.//www.uhu.es/GEIDETUR/archivos/EMILIO\%20ROMERO.pdf

San Salvador del Valle R. y Makua A. (2005): Estrategia Turismo Durango, Elaboración del plan estratégico del turismo en el municipio de Durango, Bilbao, Ayuntamiento de Durango.

Santacreu, S. (1991): "La Recuperación Del Patrimonio Industrial de la Europa Comunitaria. Balance actual y perspectivas" en M. Ramos, C. Campos, y M. A. Martín (eds.) Arqueología Industrial (Notas Para Un Debate) Málaga, Universidad de Málaga, pp. 39-62.

Sobrino, J. (2010): Revisión crítica de las estrategias para el patrimonio industrial en este nuevo siglo, I Jornada de Expertos en Patrimonio Industrial. Presente y perspectivas de futuro", La Robla/Sabero 16 de octubre. Recuperado el 1 de febrero de 2011 de http.//www.fhvl.es/fhvl/images/content/pdfs/JULIAN_SOBRINO.pdf

Soyez, D. (1986): Industrietourismus, Industrial Tourism, Erdkunde, 40(2): 105-111. Unesco (2003): Convención para la salvaguardia del patrimonio cultural inmaterial. Recuperado el 31 de enero de 2011 de http.//unesdoc.unesco.org/ images/0013/001325/132540s.pdf 
- (n.d. a): 1982 - 2000, de MONDIACULT a Nuestra diversidad creativa. Recuperada el 22 de febrero de 2011 de http.//www.unesco.org/culture/ich/index. php?lg=es\&pg=00309

_- (n.d. b): Lista de patrimonio mundial, Recuperada el 22 de febrero de 2011 de http.// portal.unesco.org/es/ev.php-URL_ID=45692\&URL_DO=DO_TOPIC\&URL_ SECTION=201.html

- (2008): Acuerdo de colaboración Unesco Docomomo. Recuperado el 7 de marzo de 2011 de http.//www.juntadeandalucia.es/culturaliaph/patrimoniocontemporaneo/ contenido.jsp?idNavegacion=documentos.jsp\&path=/patrimoniocontemporaneol contenidos/documentacion/D20080521 AcuerdoUnescoDocomomo

-_ (2009a): ¿Qué es el patrimonio cultural inmaterial? Recuperado el 8 de marzo de 2011, de http.//www.unesco.org/culture/ich/doc/src/01851-ES.pdf

_- (2009b): Intangible Cultural Heritage Domains. Recuperado el 8 de marzo de 2011, de http.//www.unesco.org/culture/ich/doc/src/01857-EN.pdf

Vargas-Sánchez, A. Porras-Bueno, N. Plaza, M. A. y García, S. (2007): Turismo industrial en la provincia de Huelva, presente y futuro, Huelva, Cátedra Cepsa Universidad de Huelva.

Vicenti, A. (2007): Perspectivas sobre la arqueología industrial, Arqueoweb, Revista sobre Arqueología en Internet, 9(1): 1-49. Recuperado el 30 de octubre del 2010 de http://www.ucm.es/info/arqueoweb/pdf/9-1/vicenti.pdf

Wagnon, C. (2001): "L'èmergence d'une curiosité pour l'industrie. Le cas de la France" en M. Damien M, y C. Sobry (eds.) Le tourisme Industriel, le touriseme du savoir-faire), París, L'Hartmann, pp.33-51. 